\title{
Towards sustainable dietary patterns under a water-energy-food nexus life cycle thinking approach
}

${ }^{1}$ UNESCO Chair in Life Cycle and Climate Change ESCI-UPF, Universitat Pompeu Fabra. Passeig Pujades 1, 08003 Barcelona, Spain

${ }^{2}$ Department of Chemical and Biomolecular Engineering, University of Cantabria. Avda. De los Castros, s.n., 39005 Santander, Spain

Corresponding author: Laura Batlle-Bayer (laura.batlle@esci.upf.edu)

\section{Highlights}

- Sustainable food systems should consider production and consumption matters.

- LCA and WEF Nexus approach are powerful tools to assess dietary patterns.

- Nutritional and health aspects could be added to the WEF nexus for dietary patterns

\section{Abstract}

The big challenge of the next decades is meeting the global nutritional demand, while reducing the pressure on food resources and the GHG emissions. In this regard, the overall goal consists of re-designing the food systems, and promoting sustainable dietary patterns is a crucial aspect. This article focuses on reviewing the state-of-the-art of the combined Life Cycle Assessment (LCA) and the Water-Energy-Food (WEF) Nexus approach in assessing the effects of diet transitions. Diet LCAs differ in methodology, design and assessed environmental impacts. The WEF nexus, which aims at finding synergies and trade-offs between the water, energy and food resources systems, has been applied to different contexts and levels. However, a limited number of nexus methods has been developed at the food and diet levels, and no commonly recognizable methodology for the nexus assessment has been achieved. An integrated Life Cycle Assessment and WEF Nexus approach can be a decisive tool to improve the understanding of the interconnections in the nexus, as it enables the consideration of entire supply chains.

\section{Keywords}

WEF Nexus, food consumption, Life Cycle Assessment, sustainability, diets, food

(C) 2019. This manuscript version is made available under the CC-BY-NC-ND 4.0 license http:// creativecommons.org/licenses/by-nc-nd/4.0/ 
Food systems are resource-intensive. They consume globally about $70 \%$ and $30 \%$ of the total global freshwater and primary energy, respectively. They are also a main driver of climate change, being responsible for $19-29 \%$ of global anthropogenic Greenhouse Gas (GHG) emissions [1]. Furthermore, these environmental pressures associated to the food systems may increase dramatically by 2050 , if the expected global socioeconomic development occurs [2].

This results in a global challenge on how to re-design food systems without threatening the environment. In most cases, strategies towards sustainable food systems focus on the production side, such as agricultural intensification [3]. However, the consumption side, meaning eating patterns, is a crucial aspect to take into account, since they are the main drivers for food production. For instance, a global transition to a "Western" style diet may increase $80 \%$ current global GHG emissions by 2050 [4]. Instead, changing towards a "healthy diet", especially in industrialized countries, together with the reduction of food waste, are crucial to ensure global food security and to avoid land clearing, and higher GHG emissions by 2050 [5].

Facing this significant role of dietary patterns, a growing amount of scientific literature has focused on assessing their environmental impacts, mostly following the Life Cycle Assessment (LCA) approach, and performing diet scenarios [6]. However, a remaining challenge is how to compare the outcomes of these studies. Diet LCAs differ in methodology and design, such as the location, type of alternative diet, system boundaries and functional unit (FU). Moreover, studies may assess different environmental impacts. In Table 1, the reported impacts within 30 comparative LCAs of diets are shown, and carbon footprint (CF) is the most commonly used (80\%), followed by Land Use (LU; 53\%) and Water Footprint (WF; 47\%), while just one article [7] considers the energy use.

To further contribute to the current debate on whether alternative healthier diets are environmentally beneficial or not, here we attempt to give a general overview of the main outcomes of the most recent comparative diet LCAs. Moreover, we aim to investigate the level of application of LCA within the water-energy-food (WEF) nexus framework. The WEF nexus, a relatively recent concept, is based on better understanding the interconnections between water, energy and food, in order to find synergies and trade-offs between these resources systems. This approach has been applied at different contexts and levels; however, a limited number of nexus methods have been published yet [8]. In this regard, this article focusses on reviewing the state-of-the-art of the combined LCA-WEF Nexus approach in assessing the effects of diet transitions. 
Table 1: List of comparative diet LCA studies, published in the last 3 years. HIC: High Income Country; UMIC: Upper-medium Income Country, LMIC: Low-Medium Income Country; LIC: Low income country. NDG-based: National Dietary Guidelines-based; E\&N-based: Energy- and nutritional-based; C-: Cradle-; FLW: Food Loss and Waste; CF:

66 Carbon Footprint; WF: Water Footprint; LU: Land Use; E: Energy Demand.

\begin{tabular}{|c|c|c|c|c|c|c|c|c|c|c|c|c|c|c|c|c|c|c|c|c|c|c|}
\hline \multirow{2}{*}{ Articles } & \multirow{2}{*}{ Country } & \multicolumn{3}{|c|}{ Type of country } & \multicolumn{3}{|c|}{ Dietary Scenarios } & \multicolumn{3}{|c|}{ Functional Unit } & \multicolumn{4}{|c|}{ System boundaries } & \multirow{2}{*}{ FLW } & \multirow{2}{*}{$\begin{array}{c}\text { Nutritional } \\
\text { Assessment }\end{array}$} & \multicolumn{5}{|c|}{$\begin{array}{c}\text { Environmental } \\
\text { Assessment }\end{array}$} & \multirow{2}{*}{$\begin{array}{l}\text { WEF-Nexus } \\
\text { Appoach }\end{array}$} \\
\hline & & HIC & & & $\begin{array}{l}\text { Other } \\
\text { current }\end{array}$ & $\begin{array}{l}\text { NDG- } \\
\text { based }\end{array}$ & $\begin{array}{l}\text { Optimization- } \\
\text { based }\end{array}$ & $\begin{array}{l}\text { mass- } \\
\text { based }\end{array}$ & $\begin{array}{l}\text { energy- } \\
\text { based }\end{array}$ & $\begin{array}{l}\text { E\&N- } \\
\text { based }\end{array}$ & $\begin{array}{l}\text { C-to- } \\
\text { FARM }\end{array}$ & $\begin{array}{l}\text { C-to- } \\
\text { RETAIL }\end{array}$ & $\begin{array}{l}\text { C-to- } \\
\text { FORK }\end{array}$ & $\begin{array}{l}\text { C-to- } \\
\text { GRAVE }\end{array}$ & & & CF & WF & LU & $\mathrm{E}$ & Others & \\
\hline Aleksandrowicza et al. [9] & IN & & & $x$ & & $\mathrm{x}$ & & $x$ & & & & & $\mathrm{x}$ & & & & $x$ & $\mathrm{x}$ & $\mathrm{x}$ & & & \\
\hline Arrieta e tal. [10] & AR & & $\mathrm{x}$ & & & $\mathrm{x}$ & & & $\mathrm{x}$ & & $\mathrm{x}$ & & & & & & $\mathrm{x}$ & & & & & \\
\hline Batlle-Bayer et al. [11] & ES & $\mathrm{x}$ & & & & $\mathrm{x}$ & & & $\mathrm{x}$ & & & & $\mathrm{x}$ & & $x$ & $\mathrm{x}$ & $\mathrm{x}$ & & & & & \\
\hline Batlle-Bayer et al. [12] & ES & $\mathrm{x}$ & & & & $\mathrm{x}$ & & & & $\mathrm{x}$ & & & $x$ & & $\mathrm{x}$ & $\mathrm{x}$ & $\mathrm{x}$ & & & & & \\
\hline Behrens et al. [13] & GLO & $\mathrm{x}$ & $x$ & $x \quad x$ & & $\mathrm{x}$ & & $\mathrm{x}$ & & & $x$ & & & & & & $x$ & & $x$ & & $\mathrm{x}$ & \\
\hline Birney e tal. [7] & US & $\mathrm{x}$ & & & & $\mathrm{x}$ & & $\mathrm{x}$ & & & & & & $\mathrm{x}$ & $\mathrm{x}$ & & $x$ & $\mathrm{x}$ & $x$ & $\mathrm{x}$ & & \\
\hline Blackstone et al. [14] & US & $\mathrm{x}$ & & & & $\mathrm{x}$ & & & $\mathrm{x}$ & & $\mathrm{x}$ & & & & & & $\mathrm{x}$ & & $\mathrm{x}$ & & & \\
\hline Blas et al. [15] & ES & $\mathrm{x}$ & & & & $\mathrm{x}$ & & $\mathrm{x}$ & & & $\mathrm{x}$ & & & & & & & $\mathrm{x}$ & & & & \\
\hline Bozeman et al. [16] & US & $\mathrm{x}$ & & & $\mathrm{x}$ & & & $\mathrm{x}$ & & & $\mathrm{x}$ & & & & & & $\mathrm{x}$ & $\mathrm{x}$ & $\mathrm{x}$ & & & $\mathrm{x}$ \\
\hline Bruno et al. [17] & DK & $\mathrm{x}$ & & & & $\mathrm{x}$ & & & $\mathrm{x}$ & & & & $\mathrm{x}$ & & $\mathrm{x}$ & & $\mathrm{x}$ & & & & & \\
\hline Chen et al. [18] & $\mathrm{CH}$ & $\mathrm{x}$ & & & & $\mathrm{x}$ & & $\mathrm{x}$ & & & $\mathrm{x}$ & & & & & $\mathrm{x}$ & $\mathrm{x}$ & $\mathrm{x}$ & $x$ & & & \\
\hline Corrado et al. [19] & IT & $\mathrm{x}$ & & & & $\mathrm{x}$ & & $\mathrm{x}$ & & & & & & $\mathrm{x}$ & $x$ & & $x$ & & & & & \\
\hline He et al. [20] & $\mathrm{CN}$ & & & $\mathrm{x}$ & $\mathrm{x}$ & & & $\mathrm{x}$ & & & $\mathrm{x}$ & & & & & $\mathrm{x}$ & $\mathrm{x}$ & $\mathrm{x}$ & $\mathrm{x}$ & & & \\
\hline He et al. [21] & $\mathrm{CN}$ & & & $\mathrm{x}$ & & $\mathrm{x}$ & & $\mathrm{x}$ & & & $\mathrm{x}$ & & & & & & $\mathrm{x}$ & $\mathrm{x}$ & $\mathrm{x}$ & & & \\
\hline Mekonnen et al. [22] & US & $\mathrm{x}$ & & & & $\mathrm{x}$ & & $\mathrm{x}$ & & & $\mathrm{x}$ & & & & $x$ & & & $\mathrm{x}$ & & & & \\
\hline Milner et al. [23] & IN & & & $\mathrm{x}$ & & & $\mathrm{x}$ & $\mathrm{x}$ & & & $\mathrm{x}$ & & & & & & & $\mathrm{x}$ & & & & \\
\hline Perignon et al. [24] & TN & & & $\mathrm{x}$ & & & $x$ & $x$ & & & & & & & & & & & $\mathrm{x}$ & & $\mathrm{x}$ & \\
\hline Reynolds et al. [25] & UK & $\mathrm{x}$ & & & & & $x$ & $x$ & & & $x$ & & & & & & $x$ & & & & & \\
\hline Ritchie et al. [26] & $\mathrm{IN}, \mathrm{DE}, \mathrm{CA}, \mathrm{CN}, \mathrm{AU}, \mathrm{US}$ & $\mathrm{x}$ & & $\mathrm{x}$ & & $\mathrm{x}$ & & $\mathrm{x}$ & & & $\mathrm{x}$ & & & & & & $\mathrm{x}$ & & & & & \\
\hline Rizvi et al. [27] & GLO & & & & & $\mathrm{x}$ & & $\mathrm{x}$ & & & $\mathrm{x}$ & & & & & & & & $\mathrm{x}$ & & & \\
\hline Rosi et al [28] & IT & $\mathrm{x}$ & & & $x$ & & & $\mathrm{x}$ & & & & & & $\mathrm{x}$ & & $\mathrm{x}$ & $\mathrm{x}$ & $\mathrm{x}$ & $\mathrm{x}$ & & & \\
\hline Song et al. [29] & $\mathrm{CN}$ & & & $\mathrm{x}$ & & & $\mathrm{x}$ & $\mathrm{x}$ & & & & $\mathrm{x}$ & & & & & $\mathrm{x}$ & & & & & \\
\hline Song et al. [30] & $\mathrm{CN}$ & & & $x$ & & & $\mathrm{x}$ & $x$ & & & & $\mathrm{x}$ & & & & & $\mathrm{x}$ & $\mathrm{x}$ & $\mathrm{x}$ & & & \\
\hline Springmann et al. [31] & GLO & $\mathrm{x}$ & $\mathrm{x}$ & $x \quad x$ & & $\mathrm{x}$ & & $\mathrm{x}$ & & & $\mathrm{x}$ & & & & $x$ & $\mathrm{x}$ & $\mathrm{x}$ & $\mathrm{x}$ & $x$ & & & \\
\hline Treu et al. [32] & $\mathrm{DE}$ & $\mathrm{x}$ & & & $x$ & & & $\mathrm{x}$ & & & & $\mathrm{x}$ & & & $x$ & $\mathrm{x}$ & $x$ & & $x$ & & & \\
\hline \begin{tabular}{|l} 
Ulaszewska et al. [33]* \\
\end{tabular} & - & $x$ & & & & $\mathrm{x}$ & & & $x$ & & & $x$ & & & $x$ & & $x$ & & $\mathrm{x}$ & & & \\
\hline Vanham et al. [34] & $\mathrm{DE}, \mathrm{FR}, \mathrm{UK}$ & $\mathrm{x}$ & & & & $\mathrm{x}$ & & $\mathrm{x}$ & & & $\mathrm{x}$ & & & & & & & $\mathrm{x}$ & & & & \\
\hline van de kamp et al. [35] & $\mathrm{NL}$ & $\mathrm{x}$ & & & & $\mathrm{x}$ & & & $\mathrm{x}$ & & & & $x$ & & & & $x$ & & & & & \\
\hline Veeramani et al. [36] & CA & $\mathrm{x}$ & & & $x$ & & & & $\mathrm{x}$ & & & & & $\mathrm{x}$ & $x$ & & $x$ & & & & & \\
\hline
\end{tabular}

*Not related to a specific country consumption patterns 


\section{Environmental impacts of diet transitions}

The effect of diet transitions differ among the country income level, diet composition and the scale of the study.

In high-income (HI) countries, dietary transitions towards reduced meat consumption, generally, decrease the CF $[11-13,17-19,25,28,35,36]$ (Table 2), LU [7,13,18,28,32] (Table 3), and WF $[15,18,28]$ (Table 4). Nevertheless, these results can vary depending on the amount and type of food groups recommended within the diet. For example, following the US dietary guidelines increases the CF, WF and energy use by $7 \%, 15 \%$ and $35 \%$, respectively [7]. This occurs because the environmental benefits of cutting down meat intake do not compensate the larger impact of the recommended higher consumption of dairy products. This is in line with findings in previous studies [37].

The same happens to upper and lower middle-income (UMI, LMI) countries. As explained by Behrens [13], the National Dietary Guidelines (NDGs) of UMI countries are similar to the ones of $\mathrm{HI}$ countries, in regard to reducing meat, dairy, oils and sugars intakes. However, the NDGs of LMI countries recommend less reduction in meat, and even some countries, such as India, Indonesia, and Romania, suggest higher meat intake than currently consumed, most probably due to protein energy malnutrition. This results in reductions of CF $[13,38]$ and LU $[9,13,20,21,30]$ when following the NDGs in UMI countries, while the opposite outcomes are found for LMI countries $[9,13,20,21]$. For example, adhering to the 2016 Chinese Dietary Guidelines increases the CF, LU and WF of Chinese diets by $7.5 \%, 54.2 \%$ and $53.5 \%$, respectively [21]. This is due to, first, the higher impacts of increased intake of recommended products (such as dairy products, nuts, fruits and seafood) than the environmental benefits of reduced meat consumption, and, second, the larger amount of food waste of the recommended products. The waste ratio of fruit and vegetables at the consumer level is $15 \%$ versus the $8 \%$ for meat products. Environmental benefits for LMI countries have been just reported for optimized diets $[23,29,30]$. Hence, optimization of diets might be a useful tool to design better environmental performing diets.

At a global scale, the composition of the alternative diet is crucial when assessing the environmental effects of a dietary shift. For example, Rizvi et al [27] estimated that 1 Gha of additional land would be required globally, if population was adhering to the USDA Guidelines [39]. Springmann et al [31] evaluated what type of dietary-shift strategies would result in the best environmental effects. They designed three types of strategies: one based on reducing animal-based products, another one based on improving the energy intake, and the third one 
102 adopting healthier dietary patterns. The last approach showed, at the global scale, the best

103 results by significantly reducing the CF, and, in less extent, LU and WF. Nevertheless, large

104 differences among countries were found. For low income (LI) and LMI countries, CF had lower

105 reductions than for $\mathrm{HI}$ countries, and LU and WF even increased with dietary shift. This was

106 related to the lower yields of legumes and vegetables, and, hence, the authors suggested the

107 need to combine strategies for dietary shifts as well as technological improvements in LI

108 countries.

109 Table 2: Effects on GHG emissions by diet shifts to alternative diets. HIST: historical; NDG: National Dietary 110 Guidelines; MED: Mediterranean diet; NDG-NM: National Dietary Guidelines with no meat; PESC: 111 Pescetarian; FLX: Flexitarian; VEG: Vegetarian; VGN: Vegan; OPT: Optimized diets. Red: Increase of GHG 112 emissions by changing to the alternative diet. Green: Decrease of GHG emissions

\begin{tabular}{|c|c|c|c|c|c|c|c|c|c|c|}
\hline & & \multicolumn{9}{|c|}{ DIET SCENARIOS } \\
\hline & & HIST & NDG & MED & NDG-NM & PESC & FLX & VEG & VGN & OPT \\
\hline \multicolumn{11}{|l|}{ HIC } \\
\hline Batlle-Bayer et al. [11] & ES & & $-17 \%$ & $-11 \%$ & & & & & & \\
\hline Batlle-Bayer et al. [12] & ES & & $-58 \%$ & & & & & & & \\
\hline Behrens et al. [13] & & & $-13 \%$ & & & & & & & \\
\hline Birney e tal. [7] & US & & $7 \%$ & & & & & & & \\
\hline Bruno et al. [17] & DK & & & & & & & $-14 \%$ & $-44 \%$ & \\
\hline Chen et al. [18] & $\mathrm{CH}$ & & $-54 \%$ & & & $-66 \%$ & $-45 \%$ & $-65 \%$ & $-83 \%$ & \\
\hline Corrado et al. [19] & IT & & & & & & & $-90 \%$ & $-90 \%$ & \\
\hline Reynolds et al. [25] & UK & & & & & & & & & $-57 \%$ \\
\hline Rosi et al. [28] & IT & & & & & & & $-34 \%$ & $-41 \%$ & \\
\hline Springmann et al. [31] & & & & & & $-82 \%$ & $-74 \%$ & $-82 \%$ & $-89 \%$ & \\
\hline van de kamp et al. [35] & $\mathrm{NL}$ & & $-7 \%$ & & $-37 \%$ & & & & & \\
\hline Veeramani et al. [36] & CA & & & & & $-37 \%$ & & $-54 \%$ & $-58 \%$ & \\
\hline \multicolumn{11}{|l|}{ UMIC } \\
\hline Arrieta e tal. [10] & AR & & $-28 \%$ & & $-62 \%$ & & & $-68 \%$ & $-73 \%$ & \\
\hline Behrens et al. [13] & $\begin{array}{c}\mathrm{RO}, \mathrm{CN}, \mathrm{MX}, \mathrm{RU}, \\
\mathrm{TK}, \mathrm{BR}, \mathrm{ZA}\end{array}$ & & $-1 \%$ & & & & & & & \\
\hline Springmann et al. [31] & & & & & & $-85 \%$ & $-73 \%$ & $-85 \%$ & $-93 \%$ & \\
\hline \multicolumn{11}{|l|}{ LMIC } \\
\hline Aleksandrowicza et al. [9] & IN & & $4 \%$ & & & & & & & \\
\hline Behrens et al. [13] & LMIC & & $17 \%$ & & & & & & & \\
\hline He et al. [21] & $\mathrm{CN}$ & $1 \%$ & & & & & & & & \\
\hline He et al. [22] & $\mathrm{CN}$ & & $7,50 \%$ & & & & & & & \\
\hline Song et al. [29] & $\mathrm{CN}$ & & & & & & & & & -12 \\
\hline Song et al. [30] & $\mathrm{CN}$ & & & & & & & & & $-24 \%$ \\
\hline Springmann et al. [31] & & & & & & $-71 \%$ & $-45 \%$ & $-71 \%$ & $-84 \%$ & \\
\hline \multicolumn{11}{|l|}{ LIC } \\
\hline Springmann et al. [31] & & & & & & $-70 \%$ & $-39 \%$ & $-70 \%$ & $-86 \%$ & \\
\hline \multicolumn{11}{|l|}{ GLOBAL } \\
\hline Springmann et al. [31] & GLO & & & & & $-75 \%$ & $-54 \%$ & $-75 \%$ & $-87 \%$ & \\
\hline
\end{tabular}


Table 3: Effect of diet shifts to alternative diets on the Land Use (LU). ORG-NM: Organic diet without meat. Red: Increase of LU by changing to the alternative diet. Green: Decrease of LU when shifting to the

\begin{tabular}{|c|c|c|c|c|c|c|c|c|c|c|c|}
\hline & & \multirow{2}{*}{\multicolumn{10}{|c|}{ DIET SCENARIOS }} \\
\hline & & & & & & & & & & & \\
\hline & & HIST & NDG & MED & NDG-NM & PESC & $\mathrm{FLX}$ & VEG & VGN & OPT & ORG-NM \\
\hline \multicolumn{12}{|l|}{ HIC } \\
\hline Behrens et al. [13] & & & $-6 \%$ & & & & & & & & \\
\hline Birney e tal. [7] & US & & $-19 \%$ & & & & & & & & \\
\hline Chen et al. [18] & $\mathrm{CH}$ & & $-32 \%$ & & & $-4 \%$ & $-5 \%$ & $-3 \%$ & $-7 \%$ & & \\
\hline Treu et al. [32] & DE & & & & & & & & & & $-45 \%$ \\
\hline Rosi et al. [28] & IT & & & & & & & $-38 \%$ & $-44 \%$ & & \\
\hline Springmann et al. [31] & & & & & & $-32 \%$ & $-27 \%$ & $-31 \%$ & $-36 \%$ & & \\
\hline \multicolumn{12}{|l|}{ UMIC } \\
\hline Behrens et al. [13] & $\begin{array}{c}\text { RO, CN, MX,RU, } \\
\text { TK, BR,ZA }\end{array}$ & & $-7 \%$ & & & & & & & & \\
\hline Springmann et al. [31] & & & & & & $-26 \%$ & $-21 \%$ & $-23 \%$ & $-24 \%$ & & \\
\hline \multicolumn{12}{|l|}{ LMIC } \\
\hline Aleksandrowicza et al. [9] & IN & & $4 \%$ & & & & & & & & \\
\hline He et al. [20] & $\mathrm{CN}$ & $2 \%$ & & & & & & & & & \\
\hline He et al. [21] & $\mathrm{CN}$ & & $54 \%$ & & & & & & & & \\
\hline Behrens et al. [13] & IN, ID & & $17 \%$ & & & & & & & & \\
\hline Song et al. [30] & $\mathrm{CN}$ & & & & & & & & & $-23 \%$ & \\
\hline Springmann et al. [31] & & & & & & $-7 \%$ & $-6 \%$ & $-7 \%$ & $-7 \%$ & & \\
\hline \multicolumn{12}{|l|}{ LIC } \\
\hline Springmann et al. [31] & & & & & & $9 \%$ & $11 \%$ & $13 \%$ & $14 \%$ & & \\
\hline \multicolumn{12}{|l|}{ GLOBAL } \\
\hline Rizvi et al. [27] & GLO & & $22 \%$ & & & & & & & & \\
\hline Springmann et al. [31] & GLO & & & & & $-11 \%$ & $-8 \%$ & $-10 \%$ & $-11 \%$ & & \\
\hline
\end{tabular}

Table 4: Effect of diet shifts to alternative diets on water footprint (WF). Red: Increase of WF by changing

\begin{tabular}{|c|c|c|c|c|c|c|c|c|c|c|}
\hline & & & & & & & & & & \\
\hline & & \multicolumn{9}{|c|}{ DIET SCENARIOS } \\
\hline & & HIST & NDG & MED & NDG-NM & PESC & $\mathrm{FLX}$ & VEG & VGN & OPT \\
\hline \multicolumn{11}{|l|}{ HIC } \\
\hline Birney e tal. [7] & US & & $15 \%$ & & & & \multirow{4}{*}{$0 \%$} & & & \\
\hline Blas et al. [15] & ES & & & $-20 \%$ & & & & & & \\
\hline Chen et al. [18] & $\mathrm{CH}$ & & $-26 \%$ & & & $3 \%$ & & $4 \%$ & $2 \%$ & \\
\hline Mekonnen et al. [22] & US & & $7 \%$ & $5 \%$ & & $-20 \%$ & & $-37 \%$ & & \\
\hline Rosi et al. [28] & \multirow[t]{2}{*}{ IT } & & & & & & & $-27 \%$ & $-22 \%$ & \\
\hline Springmann et al. [31] & & & & & & $-11 \%$ & $-12 \%$ & $-7 \%$ & $1 \%$ & \\
\hline \multicolumn{11}{|l|}{ UMIC } \\
\hline Springmann et al. [31] & & & & & & $-15 \%$ & $-17 \%$ & $-11 \%$ & $-2 \%$ & \\
\hline \multicolumn{11}{|l|}{ LMIC } \\
\hline Aleksandrowicza et al. [9] & $\mathrm{IN}$ & & $5 \%$ & & & & & & & \\
\hline He et al. [20] & $\mathrm{CN}$ & $2 \%$ & & & & & & & & \\
\hline He et al. [21] & $\mathrm{CN}$ & & $54 \%$ & & & & & & & \\
\hline Milner et al. [23] & IN & & & & & & & & & $-18 \%$ \\
\hline Song et al. [30] & \multirow[t]{2}{*}{$\mathrm{CN}$} & & & & & & & & & $-17 \%$ \\
\hline Springmann et al. [31] & & & & & & $-15 \%$ & $-15 \%$ & $-13 \%$ & $-8 \%$ & \\
\hline \multicolumn{11}{|l|}{ LIC } \\
\hline Springmann et al. [31] & & & & & & $29 \%$ & $27 \%$ & $34 \%$ & $44 \%$ & \\
\hline \multicolumn{11}{|l|}{ GLOBAL } \\
\hline Springmann et al. [31] & GLO & & & & & $-10 \%$ & $-11 \%$ & $-8 \%$ & $-2 \%$ & \\
\hline
\end{tabular}

\section{3. WEF Nexus approach at the dietary level}

122 LCA has a large potential to be used in the context of WEF nexus [12]. However, it is seldom

123 mentioned within diet LCAs. Bozeman et al. [16] are the first ones that attempt to combine LCA

124 and the WEF nexus framework for the US diets of three main demographic groups. However,

125 they do not propose a new methodology to integrate both approaches. Instead they rather 126 rename LCA impacts to WEF impacts. In addition, they do not consider the energy use, which is 
127 one of the three systems within the WEF nexus. Some other diet LCA studies $[21,30]$ refer shortly

128 to the food-health-environment nexus, although not using it,.

129 At the food product level, the development of methodologies integrating both approaches are 130 also scarce. Only two published articles $[40,41]$ were found. Frankowska et al [40] propose to 131 group LCA impacts into the three pillars of the WEF nexus, and to transform those impacts into 132 a dimensionless scores, by equally weighting the impacts by each nexus system. Regardless the 133 improvements this method might require, it is a useful tool to show the environmental impacts 134 within the WEF nexus framework.

\section{4. Concluding remarks \& recommendations}

136 A new approach to assess the lifecycle impacts of dietary patterns must be based on the nexus 137 of water-energy-food (WEF) systems. The term "nexus" implies that the action in one of the 138 systems affects the others. Therefore, any strategy that focuses on one system without 139 considering its influences to the others may lead to unintended consequences. In this regard, 140 within the context of transitioning to a sustainable dietary patterns, it is required a "nexus 141 thinking" that adopts a lifecycle approach to the water-energy-food connections. This is 142 essentially a transformative approach to the dietary pattern decision-making, and it also 143 requires extensive changes in the assessment methodology. The WEF nexus approach allows 144 assessing the lifecycle of dietary-patterns under a holistic manner considering the whole supply 145 chain. Currently, there is no universally recognised methodology for nexus analysis. However, 146 Life Cycle Assessment is particularly important for understanding the interconnections in the 147 nexus.

148 The need to shift to more environmentally sustainable dietary patterns is increasingly evident 149 but certainly not simple to achieve. Seeing that healthy dietary guidelines can be a good strategy 150 for diet transitions, we suggest that NDGs incorporate the integrated LCA and WEF nexus 151 approach. In this sense, we might argue the need to add a forth system to the WEF nexus, which would be the nutrition/health aspect of diets. 


\section{Acknowledgments}

This study is part of the Ceres-Procon Project: Food production and consumption strategies for climate change mitigation (CTM2016-76176-C2-2-R) (AEI/FEDER, UE), financed by the Spanish Ministry of Economy and Competitiveness, which aims to determine strategies to improve the sustainability of current food production and consumption.

The authors are responsible for the choice and presentation of information contained in this paper as well as for the opinions expressed therein, which are not necessarily those of UNESCO and do not commit this Organization.

\section{References}

1. Vermeulen SJ, Campbell BM, Ingram JS: Climate Change and Food Systems. Annu Rev Environ Resour 2012, 37:195-222.

2. Springmann M, Clark M, Mason-D'Croz D, Wiebe K, Bodirsky BL, Lassaletta L, de Vries W, Vermeulen SJ, Herrero M, Carlson KM, et al.: Options for keeping the food system within environmental limits. Nature 2018, 562:519-525.(**) This study assesses that food systems can increase the global environmental pressures by $50-90 \%$, if no changes are adopted. They conclude that a combination of strategies are needed to reduce these pressures.

3. Garnett T, Appleby MC, Balmford A, Bateman IJ, Benton TG, Bloomer P, Burlingame B, Dawkins M, Dolan L, Fraser D, et al.: Sustainable Intensification in Agriculture: Premises and Policies. Science (80- ) 2013, 341:33-34.

4. Tilman D, Clark M: Global diets link environmental sustainability and human health. Nature 2014, 515:518-522.

5. Bajželj B, Richards KS, Allwood JM, Smith P, Dennis JS, Curmi E, Gilligan CA: Importance of food-demand management for climate mitigation. Nat Clim Chang 2014, 4:924929.

6. Hallström E, Carlsson-Kanyama A, Börjesson P: Environmental impact of dietary change : a systematic review. J Clean Prod 2015, 91:1-11.

7. Birney $\mathrm{Cl}$, Franklin KF, Davidson FT, Webber ME: An assessment of individual foodprints attributed to diets and food waste in the United States An assessment of individual foodprints attributed to diets and food waste in the United States. 2017,

8. Albrecht TR, Crootof A, Scott CA: The Water-Energy-Food Nexus : A systematic review of methods for nexus assessment. Environ Res Lett 2018, 13.

9. Aleksandrowicz L, Green R, Joy E, Harris F, Hillier J, Vetter S, Smith P, Kulkarni B, Dangour A, Hainer A: Environmental impacts of dietary shifts in India : A modelling study using nationally-representative data Environmental impacts of dietary shifts in India : A modelling study using nationally-representative data. Environ Int 2019, 126:207-215.

10. Arrieta EM, González AD: Impact of current, National Dietary Guidelines and alternative diets on greenhouse gas emissions in Argentina. Food Policy 2018, doi:10.1016/j.foodpol.2018.05.003.

11. Batlle-Bayer L, Bala A, García-herrero I, Lemaire E, Song G, Aldaco R, Fullana-i-Palmer P: The Spanish Dietary Guidelines : A potential tool to reduce greenhouse gas emissions 
of current dietary patterns. J Clean Prod 2019, 213:588-598.

12. Batlle-Bayer L, Bala A, Lemaire E, Albertí J, García-Herrero I, Aldaco R, Fullana-i-Palmer $\mathrm{P}$ : An energy- and nutrient-corrected functional unit to compare LCAs of diets. Sci Total Environ 2019, 23:175-179.

13. Behrens P, Jong JCK, Bosker T, Rodrigues JFD, Koning A De: Evaluating the environmental impacts of dietary recommendations. PNAS 2017, 114:1341213417. $\left({ }^{* *}\right)$ This study discusses the differences of the recommendations of NDGs, and it assesses the environmental impact of dietary shifts at he global scale.

14. Blackstone NT, El-abbadi NH, Mccabe MS, Griffin TS, Nelson ME: Linking sustainability to the healthy eating patterns of the Dietary Guidelines for Americans : a modelling study. Lancet Planet Heal 2018, 2:344-352.

15. Blas A, Garrido A, Unver O, Willaarts B: A comparison of the Mediterranean diet and current food consumption patterns in Spain from a nutritional and water perspective. Sci Total Environ 2019, 664:1020-1029.

16. Bozeman J, Bozeman R, Theis TL: Overcoming climate change adaptation barriers A study on food - energy - water impacts of the average American diet by demographic group. J Ind Ecol 2019, doi:10.1111/jiec.12859.(*) This is the first study that focuses on the WEF Nexus at the dietary level.

17. Bruno M, Thomsen M, Pulselli FM, Patrizi N, Marini M, Caro D: The carbon footprint of Danish diets. Clim Change 2019, doi:https://doi.org/10.1007/s10584-019- 02508-4).

18. Chen C, Chaudhary A, Mathys A: Dietary Change Scenarios and Implications for Environmental, Nutrition, Human Health and Economic Dimensions of Food Sustainability. Nutrients 2019, 11:1-21.

19. Corrado S, Luzzani G, Trevisan M, Lamastra L: Contribution of different life cycle stages to the greenhouse gas emissions associated with three balanced dietary patterns. Sci Total Environ 2019, 660:622-630.

20. He P, Baiocchi G, Hubacek K, Feng K, Yu Y: Diets and their nutritional quality in China. Nat Sustain 2018, 1.

21. He P, Baiocchi G, Feng K, Hubacek K: Environmental impacts of dietary quality improvement in China. J Environ Manage 2019, 240:518-526.

22. Mekonnen MM, Fulton J: The effect of diet changes and food loss reduction in reducing the water footprint of an average American. Water Int 2018, 43:860-870.

23. Milner J, Joy EJM, Green R, Harris F, Aleksandrowicz L, Agrawal S, Smith P, Haines A: Projected health effects of realistic dietary changes to address freshwater constraints in India : a modelling study. Lancet Planet Heal Planet Heal 2017, 1:e26-32.

24. Perignon $M$, Sinfort $C$, El J, Traissac $P$, Drogué $S$, Darmon N, Amiot $M$, Group $S$, Amiot $\mathrm{MJ}$, Achir N, et al.: How to meet nutritional recommendations and reduce diet environmental impact in the Mediterranean region ? An optimization study to identify more sustainable diets in Tunisia. Glob Food Sec 2019, 23:227-235.

25. Reynolds C, Whybrow S, Macdiarmid J: Healthy and sustainable diets that meet GHGE reduction targets and are affordable for different income groups in the UK. Public $H$ 2018, 22:1503-1517.

26. Ritchie H, Reay DS, Higgins P: The impact of global dietary guidelines on climate 
change. Glob Environ Chang 2018, 49:46-55.

27. Rizvi S, Pagnutti C, Fraser E, Bauch CT, Anand M: Global land use implications of dietary trends. PI 2018, 13:1-12. (**) This study discusses the viability of the USDA Guidelines at the global scale. If the global population would adhere to these guidelines, not enough fertile land is currently available.

28. Rosi A, Mena P, Pellegrini N, Turroni S, Neviani E, Cagno R Di, Ruini L, Ciati R, Angelino $D$, Gobbetti $M$, et al.: Environmental impact of and vegan of omnivorous, ovo-lactovegetarian, and vegan diet. Sci Rep 2017, 7:1-9.

29. Song $G$, Li M, Fullana-i-Palmer P, Williamson D, Wang Y: Dietary changes to mitigate climate change and benefit public health in China. Sci Total Environ 2017, 577:289298.

30. Song G, Gao X, Fullana-i-Palmer P, Lv D, Zhu Z, Wang Y, Batlle-Bayer L: Shift from feeding to sustainably nourishing urban China: A crossing-disciplinary methodology for global environment-food-health nexus. Sci Total Environ 2019, 647:716-724.

31. Springmann M, Wiebe K, Croz DM, Sulser TB, Rayner M, Scarborough P: Health and nutritional aspects of sustainable diet strategies and their association with environmental impacts : a global modelling analysis with country-level detail. Lancet Planet Heal 2018, 2:e451-e461.(**) This study evaluates different strategies for dietary shifts. The authors highlight that strategies are regional-specific and they suggest the combinations of dietary shifts together with technological improvements to reduce environmental impacts in low income countries.

32. Treu H, Nordborg M, Cederberg C, Heuer T, Claupein E, Hoffmann H, Berndes G: Carbon footprints and land use of conventional and organic diets in Germany. $\mathrm{J}$ Clean Prod 2017, 161:127-142.

33. Ulaszewska MM, Luzzani G, Pignatelli S, Capri E: Assessment of diet-related GHG emissions using the environmental hourglass approach for the Mediterranean and new Nordic diets. Sci Total Environ 2017, 574:829-836.

34. Vanham D, Comero S, Gawlik BM, Bidoglio G: The water footprint of different diets within the European sub-national geographical entities. Nat Sustain 2018, 1:18-525.

35. van de Kamp ME, van Dooren C, Hollander A, Geurts M, Brink EJ, van Rossum C, Biesbroek S, de Valk E, Toxopeus IB, Temme EHM: Healthy diets with reduced environmental impact? - The greenhouse gas emissions of various diets adhering to the Dutch food based dietary guidelines. Food Res Int 2018, 104:14-24.

36. Veeramani A, Dias GM, Kirkpatrick SI: Carbon footprint of dietary patterns in Ontario, Canada: A case study based on actual food consumption. J Clean Prod 2017, 162:1398-1406.

37. Heller MC, Keoleian GA: Greenhouse Gas Emission Estimates of U.S. Dietary Choices and Food Loss. J Ind Ecol 2015, 19:391-401.

38. Arrieta EM, González AD: Impact of current , National Dietary Guidelines and alternative diets on greenhouse gas emissions in Argentina. Food Policy 2018, 79:5866.

39. USDHHS UD of H and HS: Dietary Guidelines for Americans 2010. 7th Edition. 2010.

40. Frankowska A, Jeswani HK, Azapagic A: Environmental sustainability issues in the food- 
energy-water nexus in the UK vegetables sector : Energy and water consumption. Energy Procedia 2019, 161:150-156.

41. Irabien A, Darton R: Energy - water - food nexus in the Spanish greenhouse tomato production. Clean Technol Environ Policy 2015, 18:1307-1316. 